\title{
Understanding, Identity and Ethnic of Malay-Muslims students in Thailand
}

\author{
Siriporn Pengjan ${ }^{1} \&$ Chen Zhixai $^{1}$ \\ ${ }^{1}$ College of Public Administration, Huazhong University of Science and Technology, Wuhan, Hubei, People's \\ Republic of China \\ Corresponding author. Siriporn Pengjan, College of Public Administration, Huazhong University of Science and \\ Technology, Wuhan, Hubei, People’s Republic of China. E-mail: pookubsp11@gmail.com
}

Received: February 28, 2019

Accepted: March 23, 2019

Online Published: April 3, 2019

doi:10.5539/ach.v11n2p1

URL: https://doi.org/10.5539/ach.v11n2p1

\begin{abstract}
This article aimed to study the adaptation process of youths from the three southern border provinces who moved to other areas of Thailand, whose have Islam religious and Malay- Muslims ethnic group who move to study at Prince of Songkhla University Surat Thani Campus (PSU), Thailand. The study based on qualitative, focus group was analyzed using analysis four misunderstanding issues to finding level of adaptation as 1) Teacher day's observation 2) The activity of welcoming freshmen 3) Hijab and 4) Halal food with Youths, aged 18- 24, it found that had three levels of adaptation: The first level, during the first month. They are attached to the identity of the ethnic group. The second level, they have adapted to the identity of the ethnic group. At the same time, they have adapted to the culture or culture to the third level, and when they are in the area for longer, they see themselves as part of a new culture. Moreover, this article will help to open up new perspectives for people of different religions, or individuals in Thai society to better understand the way of life, culture, and differences of Muslim students. Together, people of different ethnicities can learn and accept their cultural differences so that they can live together peacefully.
\end{abstract}

Keywords: Identity, Religious, Ethnic, Adaptation process, The Malay Muslim Students

\section{Introduction}

"On an interviewed day for university entrance into Prince of Songkla University, Suratthani Campus (PSU), Thailand where there are a lot of high school graduate students from all over the country waiting for the interview, a young the Malay-Muslim girl from Pattani Province appears among them. Considering her attire, she stands out with a long sleeves blouse, long pink skirt down to her ankles and covering her hair with Hijab. While waiting, she speaks to her father who accompanies her in Meyawe dialect, and when she meets other the Malay-Muslim, she greets them with Muslim greeting instead of ordinary Thai "Wai" Upon the interview completion, she and her father go straight to the Muslim food place." However, education is even included in the definition of education development for many the Malay-Muslim students as many describe a child with academic success as one who is on "the good path" (Azmitia \& Brown, 2000).

One young the Malay-Muslim Students woman who is from three southern border provinces moves to have higher education in Prince of Songkhla University, Suratthani Campus (hereafter PSU). With the physical appearance of attires showing the differences along with speaking dialect that is unfamiliar to ordinary Thais and showing her lifestyle that based on religious guidance, it subsequently leads to the question that she asks herself "Being as I am, would others in the university be surprised and would they think I am strange? Would they detest me?" She uncovers some of her doubts that can further arouse a new issue of what makes this the Malay-Muslim young woman come up with such a question of disappointment or what is the conflict between Muslim and non-Muslim, or Buddhist, who are the majority in the university and Islamic belief who are the minority in the place.

One of the fastest growing religions as Islam, Islamic people are rigorous in religious practices or rituals; that is, all performances must be following the will of Allah through the practices of Prophet Mohammad, the messenger (Chaudhury \& Miller, 2008). On the contrary, other religious performances which included in the prophet's possible patterns are strictly considered prohibited. Thus, it can be easy to say that a good Muslim means an individual who lives his/her life following the religious guidance of Islamic religious commandments, or another word, Muslim ways of living. However, this can be an issue for a Muslim who is very strict in religious practices 
and has to move to other areas to pursue and achieve his/her education as well as to study in places like PSU. Migration to a new society can be complicated for adolescents as they are also experiencing a critical transition to adulthood (Khatereh et al., 2017). This article, therefore, aims to create understanding while learning the Thai Muslim identity through the frame of thoughts on an adaptation by four issues it misunderstands of youths from three border provinces who are Malay-Muslim student's followers and being strict on performing Islamic Practices, and they have to relocate to an area of different identities which is PSU. The study includes how members of the targeted group adapt themselves when they are among students of Buddhism, and the location of the university is in Suratthani Province, where the number of the Muslim population is minimal.

This study focus is on an adaptation process with four issues misunderstand of the Malay Muslim students from the three southern border provinces and seeking and finding problems are conducted to offer ways of living together in the multicultural society that can further lead to concrete guidelines and recommendations. Thus, it is exciting to learn about Muslim students who represent Malay ethnicity and have to be far away from home to study and become a sample group of this article.

The purpose of this research was to study the target groups, how to adjust to their studies at the university, which area of the students was mostly Buddhist students and the area of the university located in Suratthani. Target groups in research are selective follow:1) The Leader of the Muslim Club and the Vice Chairman of the Club as two students 2) The members of the Muslim Club as four students and 3) The Muslim Students who are studying at first to the fourth year of PSU. The ages range from 18 to 24 years, who were studying are the Faculty of Liberal Arts and Management Sciences and the faculty members of the Faculty of Science and Industrial Technology as 12 students, the total numbers of 20 students. Besides, the researchers used participatory observation during group discussions and focused group using an analysis of four issues, which may lead to the problem of coexistence. There are four issues as follows: 1) Teacher's Day Observation 2) The activity of Welcoming Freshmen 3) Hijab 4) Halal food as well as information from relevant documents and research. The data is then analyzed, examined, discussed and summarized. The Malay Muslim students' groups in that there is an additional focus on developing an individual relationship with Allah as well as on engaging in an autonomous religious developmental experience as opposed to merely replicating early spiritual socialization experiences and family values (Ali, 2006; Chaudhury and Miller, 2008; Duderija, 2007; Peek, 2005). The Malay Muslim student's ways of life are firmly attached to the principles of performances based on religious beliefs and practices, and such religious performances identify their uniqueness.

\section{Literature Review}

Accordingly, this research opens various adaptation views or perceptions to create mutual understanding Identities, Religion, and Ethnic in between people of different identities especially is Muslim; which can summarize as the following.

Identity is an individual's feeling, and thoughts toward self of "Who am I?" which happens when the individual interacts with others, and such a person looks through him/herself while others also look on. Identity needs self-awareness and certain selective backgrounds, for example, we must reveal ourselves or intentionally accept the identity we choose to be. The importance of self-revealing is to indicate our identity that we belong to one group and how different we can be with other groups, and the "Who am I?" in the eyes of others.

Identity theory has stated that identity is a non-natural occurrence, but it is a cultural creation at a certain period whereas culture is a social construct that is unfixed but ongoing with a pattern of "circuit of culture" Thus, all identities have a "produced" The process that can be consumed and regulated within a particular culture. Creating various meanings through different methods of symbolic systems of representation related to positions or places of identities that we choose are the way to construct our identities (Chalardchai, 2007) and indicated that community lifestyle is a culture. The culture is the way of living together among a group of people that the people's lifestyle correlated with their surroundings which comprise of mutual beliefs, mutual value systems, careers, languages, healthcare, and traditions, or another word, culture is about economy, spirit, society, environment, and health that integrally linked. Hence, while culture is about the integration of the entire ways of the living, modern economy, as currently being understood, seems to separate the two issues by placing money as a core issue and the Malay Muslim lifestyle becomes a designation.

The Malay Muslim students' identity held and linked with the core of being "Malay ethnicity." Through their speaking dialect or another word, the main component of Malay culture is Melayu language), Islamic belief, food, clothing, and its practices. It can say that whoever speaks the Melayu language and chooses to have Malay lifestyle, that individual is a Malay, yet, if a person can talk to Malay but being non-Muslim, that person is not Malay. 
The Malay Muslim lifestyle is engaged with three Islamic cores: the principle of faith, the principle of religious commandments and principle of ethics and morals which are the duty that all Muslims must understand and perform. Having faith in Islam must be exhibited and confirmed through words by conducting self-pledging and performing different acts of praying, fasting, making Zakat and attending Haj. Furthermore, this study has argued that Islam becomes a conscious element for Muslims in the three southern border provinces in part due to evolving social interactions related to their religious and cultural minority status (Daiute et al. 2010; Duderija, 2007; Peek, 2005). Moreover, daily performance is mandatory to be by the example set by Prophet Mohammed. Islam also preaches that human beings are sent to live in this earth temporarily, and they live differently regarding knowledge, capability, status, and opportunity in which the differences are aimed for humans to have a mutually positive relationship. The same thing that all humans receive throughout their lives is the test from Allah to exhibit the being of a good Muslim.

\section{Method}

The qualitative method by focus group, its allowed the researcher to directly interact with a targeted group which is part of this research reveals different issues that may cause misunderstanding and further leads to problems in living together as well as contradiction against Muslim and some non-Muslim. As for this research, four points explained. It is worth mentioning here that all these issues create an uncomfortable feeling for Muslim students because being the university students they are obliged to comply with ongoing institutional practices and traditions. On the contrary, they are Muslim who are loyal to their ancestors' beliefs of a Muslim lifestyle as well as being "Malay ethnicity." The issue seems normal, simple and no complication for students of Buddhist believers, yet for Muslim ones, such a simple thing can be a big problem for them.

\subsection{Key Informants}

There were includes 1) the leader of the Muslim Club and the Vice Chairman of the Club. 2) The members of the Muslim Club 3) The Muslim Students who are studying at first to the fourth year of PSU from faculty of Liberal Arts and Management Sciences and faculty of Science and Industrial Technology. The total numbers of 20 students as ten males and ten females, who ages range from 18 to 24 years.

\subsection{Data Collection}

This study used participatory observation during group discussions and focused group, which using a descriptive analysis of four issues to obtain a deep understanding of a young Malay Muslim student's adaptation. For the objectives of this study, we chose to analyze to suit our inquiry into discovering and ways of Muslim life of the Malay Muslim students growing, particularly the challenges they face in adjusting to the new culture of the modern university (Beck, 1992; Lopez, 2004). The qualitative research for better generalization and the syntheses of phenomena versus individuals as invariant structures (Sousa, 2014) and elaborates on reflective matters experienced by the researchers (Englander, 2012).

\subsection{Data Analysis}

This study analyzed the data qualitatively, using content analysis from the data collection that was carried out according to the following steps 1) to read and review all protocols to acquire a feeling for finding issues that create incomprehension between religions. 2) To explore target groups and to set the samples 3) to developing the question 4) Focus group; the researcher to directly interact with them with a targeted group 5) Collected the issues 6) Analyze together with four target issues. Also, 7) to find the balance between finding themes that are incomprehension between religions. Finally, the study described the Malay Muslim who affected by the understanding issues and seeking problems are conducted to offer ways of living together.

\section{Results}

\subsection{Teacher's Day Observation}

Often, The Malay Muslim students have suspiciously been looked at from non-Muslim other religious with a question why don't they participate in this event? Since such participation is a tradition that all good students should perform to show their gratitude toward teachers who provide the knowledge. Muslim followers are as much a student as others, and this is a good activity that all students should take part in. Why all Malay Muslim students exclude themselves and turn to perform other activities where there are entirely Muslim teachers and students participate? Moreover, why are they conducting discrimination?

With such inquiries, many scholars have searched for answers and explained that Islamic followers are not allowed to perform any activities if they are not stated in the Pro-visions by Allah, mainly, the performance that is involved with others of different religions or it is the practice of other religion. Another inquiry then arises: "What is Islamic 
Teacher's Day Observation?" The answer is "Prophet Muhammad" is a teacher of humanity, and he has never had anyone perform gratitude practices on him or to commemorate him or order anyone to treat him on a specific set date especially. The evidence of the prophet statement does not reveal any permission to perform such activity. Besides, the prophet's associates have not performed such activity. This clarification also means that Teachers are the guides who direct people to be loyal and respectful to Allah, the one and only. Teachers must do whatever it takes to make people understand Islam. Therefore, teachers are acting as a representative of the prophet who gives people a proper direction and is an excellent example to others. Thus, teachers in Islamic points of view do not need the practice of Teacher's Day Observation because respect should be given only to Allah.

Moreover, there is no other provision from Allah to do so. Therefore, the Prophet Mohammad's practices are concurrently agreed and that there is no example of such practice on Teacher's Day Observation to be followed in Islam. So, the explanation is that. "Teacher's Day Observation ceremony for Muslim students is unnecessary" The adaptation to maintain the identity of the Malay Muslim students for this issue. It is essential to follow:

"Teacher's Day Observation period is very tired most of the explanations for the reasons for not being able to participate in Teacher's Day Observation or the reasons for not being able to contribute to Teacher's Day Observation I have to explain every time. I have to understand and not understand each other. However, most of my friends understand it. However, sometimes they go to visit friends who are doing Teacher's Day Observation. To encourage and buy foods for friends during the activity. All my friends are tired of doing things. The rice service on the water during the activity is probably the best solution, and it is a good one."

(Target group, Interview: 10th June 2018).

\subsection{The activity of Welcoming Freshmen}

The welcoming freshman is a tradition that has continued in many institutions, and there are many welcoming methods. In some universities, such activity conducted by providing assistance and a warm welcome to impress their freshmen in which this tradition accordingly helps the newcomers in adjusting themselves and simultaneously become unison. Organizing welcoming freshmen activity aims to create a warm welcome for first-year students as well as to have the newcomers obey and strictly follow their senior students. Any violation is considered to disobey or disrespect to the older students. PSU organizes this welcoming activity aiming to create unity between first-year students and older students. Within the Malay Muslim points of view, the activity of welcoming first-year students originates from other culture, not Islam. Unavoidably, there is negligence toward right or wrong in Islamic directions, such as, the uniting of men and women as there is no separation of gender in this event, in fact, they join in working together and having physical closeness which is unacceptable in Islam. Uniting and being touched by the opposite sex are wrong and against religious practices which can go as far as sexual misconduct in the future. What happens at the time is considered crucial.

The adaptation of the Malay Muslim students when attending such activities is partly reflected in the same people. Freshman's 1st Year Acceptance of self-identity as a student is a sign of adapting to volunteerism. At the same time, it is reflected in the form of the Muslim Club of the University, which is the cooperation of the Student Affairs Organization. To keep watch and control to follow the course of religion. This issue is a significant adaptation of Muslim students, including the "Who am I?" As well as "1st-year student of PSU and Muslim students along the way."

\subsection{Hijab/Scarves}

Covering their heads with scarves for all Muslim female students is strange for those who are from other regions, yet at some places, it does not seem to be an issue. Although Muslim students dress up differently from regular university female students' attires whereas Hijab/scarves context has been continuously creating various disputes, fortunately, there have been no disputes in PSU. Nevertheless, some students in the targeted group provide specific information occurred with her classmates in the case of "Banning Hijab" that a small group of the Malay Muslim female students attending university in the north-East of Thailand and majoring in Industrial Technology in which some subjects involve the work with machines where the reasonable regulations on security require short sleeves clothes and non-Hijab/scarves which, of course, against Muslim practices. Muslim practices, the solution is searched. Sadly, it ended with the ultimate statement by the teacher that orders student to choose between wearing Hijab or no class attendance.

Thai people call Hijab a "scarf" or "headscarf" which does not define its actual meaning. Hijab means to "cover," not only the clothes that cover the external parts of a body but also the manner, body posture, as well as an internal feeling of shame and concentration. Hijab is like a tool to help young Muslim women become cautious and focused 
themselves on being within the religious principles. They are aware that they are the representatives of Allah in this world and all their expressions and images reflecting their behaviors are the overall picture of Islam. Thus, covering heads with Hijab does not only mean a cloth to place on a body, but it also indicates an act of acceptance of all principles that come with it.

\subsection{Halal Food}

Upon having meals at Thai Buddhist food shops, sharing food or being invited to eat is immediately rejected by the Malay Muslim students. The Muslim ways of living on food are to consume "halal" Food specifically, and the forbidding consumption is "Pork" Because Muslims believe that pigs are a four-footed animal that eats everything and they contain many fatal diseases within their bodies. However, if it is in a severe situation where it is impossible to find food and nonfood consumption means fatality, eating pork is allowable. On the other hand, a beverage of all alcohols such as liquor, beer. That was forbidden even if it is for mixing with others and becomes medicine. Such forbidding includes being parts of producers, distributors, servers, or service providers. In cooking "Muslim food," the cooks must solely be a Muslim, and they have to make food following Islamic principles including clean cooking and clean ingredients while assuring no diseases. It can summarize that Muslim food must be following Muslim provisions, that is, non-mixture of forbidden items such as pork, pig fat or other pig products as well as all animals' blood. Food made from deadly toxic vegetable, food or beverage containing alcohol and food having critical components is all forbidden. An only one Muslim food shop in the university canteen, comparing to the number of 419 Muslim students, can have a substantial impact to the students, especially when the university regulation states that all freshmen must stay in the university dormitories within the university parameter and that they are not allowed to use motorcycles. All these affect the Muslim students' or the Malay Muslim students' lifestyle, particularly on the consumption of those mentioned above "Halal Food."

\subsection{Summary of the section}

Based on the four issues along with the brief explanation to indicate the Muslim lifestyle of the Malay Muslim students, they reveal practices attaching with their beliefs which are susceptible issues and any ignorance can finally lead to a disaster, wherein worst-case scenario, there could be evidence where the Malay Muslim students may have to choose between being a university student and being a Good Muslim. In either choice, it is a disadvantage to the students because if they choose to continue being students, they have to give up their identity but if the students choose to maintain their identity, they have to stop their roles of being a student. Eventually, who is going to be responsible for the students' future knowing that they are the hope for the future of their families? The adaptation is, therefore, a problematic issue for the Malay Muslim students, especially during the first months of moving into the new area. If they can get through the testing of the first month's period, they should be able to maintain their status of being good students and being praised as a good Muslim. At an initial stage, all involved parties must learn and sincerely want to create a mutual understanding which might be difficult for Thai Buddhist students having the role of a "host" to be aware of the diversities occurring in their daily life. Thus, one of the students in the targeted group said

"A society of learning is the society of intelligence containing those who can comprehend their mutual differences if there is adequate justification along with honest communication with an attempt to understand visitors to reveal good hospitality."

(Target group, Interview: 10th June 2018).

However, past evidence shows that when differences occur, discrimination arises along with misunderstanding and there is no attempt to look for a mutual solution or to understand the dissimilarities to create the living together effectively" From the four issues discussed in the analysis and adaptation process. The findings from this research show that the Malay Muslim students from three southern border provinces with Malay ethnicity migrate to different areas of religion and ethnicity to three different levels.

4.5.1 Stage one: The first month that is attached to the identity of the ethnic group. Moreover, take a new culture or come in a little or to reject the new culture or the central culture as Teacher day's observation, Halal food, Chorus singing activities of the University and Hijab, etc.

4.5.2 Stage two: during the first month in different areas, there are adaptations to preserve the identity of the ethnic group. At the same time, it has adapted to the new culture or the central culture, or the assimilation culture as, from the students who attended the conference. They are not attached to their ethnic identity or Assimilation culture as the activity of welcoming freshmen and language used etc.

4.5.3 Stage three: within the period of study and live in Suratthani. Considering that they are part of a new culture or a significant culture. The culture called the culture of integration Melayu language used "Tai Language" etc. 


\section{Results and Discussion}

Our findings suggest that nowadays, expressing ideas or views can sometimes lead to conflict that can further extend to the crucial dispute which is because people do not open themselves to learn about one another. That is a conclusion being gained from the focused research group as "Perceiving only the differences and the causes of conflict on the surface, and ignoring the roots of culture, traditions, and origins, yet concentrating only on self without paying attention to impacts toward others while disrespecting others' opinions on being different from self are the best source of destruction on the relationship of living together or living together on the basis of diversity which might be the effectiveness of the future Thai society." (Target group, Interview: 10th June 2018).

Creativity and avoiding violence, creative learning transfer should be conducted. The roots or origins of all contradictory contexts must be scrutinized by both visitors and hosts which include perceivable issues; issues with deeper roots regardless of the ones that are the impact of social structures or cultural transmission; problems showing has implications toward others; and willingly and genuinely listening and accepting others' different ideas without prior judgment. All these practices will create peacefulness in Thai society.

The unrest situation in the three border provinces during the past 14 years has made others in Thai society create pictures of Muslim living in the provincial areas as people of troublemakers who focus only on self-benefit and disrespect of the laws. Such images come from what the media reveals. Prejudice happens everywhere, and what people from other areas perceive from the media, bias and different negative impressions, e.g., hatred, fear, unclear obtained information or confusion are implanted in the people's mind that eventually turn into stereotype toward Islamic believers of the three border provinces. Of course, The Malay Muslim students from the areas are unexceptional. Such pictures along with traditions and practices that the three border provinces students perform and their identity which might be different from other Muslims' lifestyle could make it more difficult for them to participate in some activities such as welcoming first-year students. It is because deciding to participate in events means an uncomfortable feeling from knowing that it is against their religion, but Non-participation can lead to misunderstanding among peers who are not aware of the Malay Muslim lifestyle. Such a situation makes life difficult for The Malay Muslim students.

\section{Conclusion and Recommendation}

From the four issues discussed, together with the adaptation process of students moving from the three southern border provinces, whose have Islamic religious and Malay ethnical to study at Prince of Songkla University Suratthani Campus There are only three levels of adjustment and level of adjustment. It is a model called "A Cultural-Ethnic Identity Typological Mode," which ethnic-Oriented Identity, the attachment to the identity of the high self-ethnic group. This model, John Berry, is used to study the adaptation of minority groups in the central culture, this is in line with the first phase of the migratory population, with the first months of the year is closely linked to the identity of the ethnic group. Moreover, take a new culture or come in a little or to reject the new culture or the central culture; this is according to Teacher's Day Observation and Halal Food. (Rujirat, 2009).

\subsection{Bicultural Identity}

It is the preservation of the identity of the ethnic group. At the same time, it has adapted to the new culture or mainstream culture or called the culture of harmony. In the first months of the same period, there were adaptations to preserve the identity of the ethnic group. At the same time, it has adapted to the new culture or the central culture; this is according to the activities of welcoming freshen. (Wisoot, 2010).

\subsection{Assimilation Identity}

It is not inherent in its ethnic identity. They see themselves as part of a new culture or culture. The culture of self-has swept away or called the culture of integration. When asked about the fourth-year students, the only answer that corresponded with the level of adjustment was the students who shared the groups shared a belief in the four-year study. They are not attached to their ethnic identity; this is according to the Melayu language (Khatereh, 2017).

\subsection{Marginal Identity}

It does not feel like a member of the entire ethnic group. Moreover, in a new culture call this type of adaptation a Marginal Man, but the sample is not consistent with this pattern according to Tien and Sim's research (David et al. 2010: 201-215). The starting point is that all must learn to make real understandings.

Adaptation is a problematic proposition for the Malay Muslim students, especially during the first month of migration to other areas but when I passed the first test. Students will be able to find a way to maintain good student status and maintain a well-respected Muslim path. The starting point is that all parties must learn to make a 
real understanding; this may be equally difficult. So, the higher education society, the learned society, can understand each other's differences if there is an explanation. Enough and they communicate with sincerity and understanding of both the visiting and the kind hosts. "However, in the past, when there are many differences, often leads to alienation and lack of mutual understanding because theirs do not try to find a solution to the problem together. They do not try to understand each other from different points of view, and its difference will be making conflict and violence to each other" (PSU Muslim Club, Interview: 10th June 2018)

The Malay Muslim students' main problems in migrating to study in other areas are the ability to understand the host or insufficient communication to understand each other effectively and if it is in terms of communication which comprises of sender, information sent, channel and receiver, both the misunderstanding and the exit can occur at any of these four issues. The most important thing in this context is the sender who is the Malay Muslim students from three border provinces, and the receiver or the peers who are non-Muslim as well as university personnel along with people residing around the university area who enable to comprehend the living diversity and some limitations. Such comprehension can break the prejudice derived from a misunderstanding which can affect managing problems and further leads to better understanding and sympathizing. (Sudarat, 2016).

Thus, the institution's key role toward identity and cultural diversities is to create multicultural society as well as to focus on organizing the education of multicultural learning. (Unicef, 2011). The study on the multicultural pattern seen as mandatory as it is the readiness creation in overall areas aiming for the most effective multicultural society in which this researcher has found that it should operate as the following.

(1) The Knowledge Construction Process: in this process, curriculum teachers play an essential role in helping students to understand the background of misunderstanding correctly, for example, issues on components of nationality, ethnicity, gender, and social classes of a person or a group of people. (Saemah, ed.al. 2011). As for a social construction in this dimension, university and curriculum teachers must change the learning content of relevant courses or basic courses is mandatory for all students in the subjects of multi-cultures and fundamental human rights, for instance, the subject of living skills, universal laws. Alternatively, another subject that directly involved, such as social science which includes the knowledge of dissimilarity, human prestige, honor the differences, etc. whereas substantial contents that link with the existing subject, i.e., basic political science, politics and governance, common law, etc. or even activity-based theme must be focused. All these points must be implanted in the learning under a perception of "multicultural society of living together under dissimilarity" (Jakob, 2012).

(2) An Empowering School Culture and Social Structure (Betül, 2015) this is a dimension that focuses on cultural adjustment in school organization to suit various groups of students integrally and equally. School administrators, teachers, university personnel, parents, as well as students should take parts in a decision process; creation of cooperation atmosphere; adjustment of media pattern that facilitates all university members; adjustment of curriculums and teaching methods along with activities being responsible by sections, groups or organization within university such as increasing multicultural activities, knowledge exchange to understand identity of Buddhist, Muslim and Christian students, etc. which are under student council and student activity development program.

(3) Opening areas to disclose dissimilarity among people in the same society: this dimension belongs to students and under student activity campaign. It is to implant and boosts the ideas of listening to the minority; create consensus under participation; conduct vision adjustment or adjust old activities toward construction of areas of differences such as arranging a field trip for identity and cultural learning to extend the comprehension space on dissimilarity of identity. (Richard et al., 2017)

Subsequently, the pictures of the Malay Muslim female student wearing Hijab, speaking Melayu (or Jawi), consuming Halal food and greeting others with Salam will no longer be a dissimilarity. This particular student who represents Malay ethnicity moves to areas of a different culture to study is a visitor while another student who is Thai Buddhist, speaks southern dialect, wears a short skirt, greets her teachers or senior students with "Wai" believes in Buddhism, loves her identity of being southern lady' is a host. An initial stage of learning and living together is an important "adjustment process." Although it is imperative to conduct self-adjustment under new surroundings and mechanisms of behavior, idea construction, practical ways, etc., both Thai Buddhist and the Malay Muslim students need to learn to live their lives among dissimilarities. Their stepping over the differences is a challenge aimed to make the Thai society becomes a multi-cultural society that pays attention to happily residing together under diversities. That is, visitors, understand and open their lifestyles and identities while people in the area do the same. Thus, a parameter of PSU becomes the study case, and it can be a guideline in constructing a pattern of living together among students of different identities. If only all students think and are aware that 
regardless of year of study, faculty, major or where their domiciles or their backgrounds are, they are brothers and sisters and peers of the society who possess prestige and equality of being human. Faiths or provisions bring them to interact, confront and live together, understand one another through learning by understanding each other to live in such a multicultural society, this is a training ground that initially trains them and makes them ready to go out to the big full world full of infinite diversities.

\section{Acknowledgments}

I would like to thank all my professors and colleagues who always encourage me to carry out this research paper. Moreover, I would like to show my sincere gratitude to the participants who actively helped me and answered their focus group regardless of their busy schedules.

\section{References}

Ali, S. (2006). Psychology and Sunni-Muslims. In E. Dowd, S. Nielsen, E. Dowd, \& S. Nielsen (Eds.), the psychologies in religion: Working with the religious client, New York., NY: Springer.

Azmitia, A, and Brown, J. R. (2000). Latino immigrant parents' beliefs about the "path of life" of their adolescent children. In J. M. Contreras, K. A. Kerns, \& A. M.Neal Barnett (Eds.), Latino children and families in the United States. Westport, CT: Praeger Press.

Beck, C. T. (1992). The lived experience of postpartum depression: A phenomenological study. Nursing Research, 41, 705-13.

Benner, A. D., Boyle, A. E., and Sadler, S. (2016). Parental involvement and adolescents' educational success: The roles of prior achievement and socioeconomic status. Journal of Youth and Adolescence, 45, 1053-1064.

Berry, J. (1997). Immigration, acculturation, and adaptation. Applied Psychology, 46, 5-34.

Berry, J. W, and Sabatier, C. (2010). Acculturation, discrimination, and adaptation among second-generation immigrant youth in Montreal and Paris. International Journal of Intercultural Relations, 34, 191-207.

Berry, J. W. ( $\left.\begin{array}{llll}2 & 0 & 0 & 8\end{array}\right)$. Globalization and acculturation. International Journal of Intercultural Relations, 32, $328-36$.

Berry, J. W. (2005). Acculturation: Living successfully in two cultures. International Journal of Intercultural Relations, 29, 697-712.

Berry, J. W., Kim, U., Minde, and T. Mok, D. (1987). Comparative studies of acculturative stress. International Migration Review, 21, 491.

Berry, J. W., Kim, U., Power, S., Young, M., and Bujaki, M. (1 98 9). Acculturation attitudes in plural societies. Applied Psychology, 38, 185-206.

Betül Balkar. (2015). defining an empowering school culture (ESC): Teacher perceptions. Issues in Educational Research, 25, 3 .

Chalardchai Ramithanon. (2007). Identity, Cultural and Changed, Thailand. Retrieved from http://wsccmu.com/s/20_.pdf. [Accessed 30 July 2018].

Chana Etengoff, and Colette Daiute. (1997). Sunni-Muslim American Religious Development during Emerging Adulthood. Journal of Adolescent Research, 28, 690-714.

Chaudhury, S. R., and Miller, L. (2008). Religious identity formation among Bangladeshi American Muslim adolescents. Journal of Adolescent Research, 23, 383-410.

Cummins, H. A. (2005). Mommy tracking single women in academia when they are not mommies. Women's Studies International Forum, 28, 222-31.

Daiute, C. (2010). Human development and political violence. Cambridge, UK: University Press, Cambridge.

David, Maya Khemlani and Wendy Yee Mei Tien. (2010). Perceptions of ethnic otherness: A study of Malaysian children. In Maya Khemlani David, James McLellan, Ngeow Yeok Meng, Lean Mei Li \& Wendy Yee Mei Tien (eds.), Ethnic relations and nation building: The way forward, Petaling Jaya: SIRD, 183-200.

Duderija, A. (2007). Literature review: Identity construction in the context of being a minority immigrant. Immigrants \& Minorities, 25, 141-62.

Englander, M. (2012). The interview: Data collection in detailed phenomenological human scientific research. Journal of Phenomenological Psychology, 43, 13-35. 
Jakob Lauring and Jan Selmer. (2012). Positive dissimilarity attitudes in multicultural organizations: The role of language diversity and communication frequency. Corporate Communications: An International Journal, 17, 156-72.

Khatereh Arbabi, Christine Jean Yeh, Zuria Mahmud, and Amla Salleh. (2017). From Monocultural to Multicultural: Adaptation of Iranian Immigrant Adolescents in Malaysia. Journal of Adolescent Research, 32, 371- 402 .

Lopez, K. A., and Willis, D. G. (2004). Descriptive versus interpretive phenomenology: Their contributions to nursing knowledge. Qualitative Health Research, 14, 726-35.

Peek, L. (2005). Becoming Muslim: The development of religious identity. Sociology of Religion, 66, 215-242.

Phinney, J. S., and Chavira, V. (1 9 95). Parental ethnic socialization and adolescent coping with problems related to ethnicity. Journal of Research on Adolescence, 5, 31-53.

Richard Harris and Dewi Owen. (2017). Implementing a Multilevel Index of Dissimilarity in R with a case study of the changing scales of residential ethnic segregation in England and Wales. Environment and Planning B: Urban Analytics and City Science, 45, 1003 - 21.

Rujirat Kammayee. (2009). Cultural Adjustment of University Students from the Three Southern - Border Provinces in Bangkok. (Unpublished master's thesis). Chulalongkorn University, Thailand

Saemah Rahman, Ruhizan M Yasin and Kamaruzaman Jusoff (2011) Knowledge Construction Process in Online Learning. Middle-East. Journal of Scientific Research, 8, 488-92.

See Hoon Peow. (2009). Politics of Religious and Ethnic Identity the Cases of Southern Thailand and Southern Philippines. The Journal of International Social Research, 2, 9.

Shumow, L., and Miller, J. D. (2001). Parents' at-home and at-school academic involvement with young adolescents. The Journal of Early Adolescence, 21, 68-91.

Sousa, D. (2014). Validation in qualitative research: General aspects and specificities of the descriptive phenomenological method. Qualitative Research in Psychology, 11, 211-27.

Stetsenko, A., Arievitch, and I. M. (2004). The self in cultural-historical activity theory: Reclaiming the unity of social and individual dimensions of human development. Theory \& Psychology, 14, 475-503.

Stodolska, M. (2008). Adaptation problems among adolescent immigrants from Korea, Mexico, and Poland. Journal of Immigrant \& Refugee Studies, 6, 197-229.

Sudarat Tuntivivat. (2016). the inter-relationship between violence and education amidst armed conflict in Southern Thailand. Journal of Aggression Conflict and Peace Research, 8, $269-78$.

Telzer, E. H., and Fuligni, A. J. (2009). A longitudinal daily diary study of family assistance, and academic achievement among adolescents from Mexican, Chinese, and European background. Journal of Youth and Adolescence, 38, 560-71.

Thomas Hadjistavropoulos, Sharon Kaasalainen, Tamara Sussman, Genevieve Thompson, Lorraine Venturato and Abigail Wickson-Griffiths. (2019). Mind the gap: is the Canadian long-term care workforce ready for a palliative care mandate?. Ageing \& Society, 1-21.

Ungpakorn, G. J. (2007). A Coup for the Rich: Thailand's Political Crisis. Bangkok, Thailand: Workers Democracy Publishing.

Unicef. (2011). Tackling Violence in Schools: A global perspective bridging the gap between standards and practice. New York: Office of the Special Representative of the Secretary-General on Violence against Children.

Vedder, P. (2005). Language, ethnic identity, and the adaptation of immigrant youth in the Netherlands. Journal of Adolescent Research, 20, 396-416.

Vergote, A. (1996). Religion, belief, and unbelief: Psychological study. Amsterdam, Netherlands: Leuven University Press.

Waterman, A. S. (1988). Identity status theory and Erikson's theory: Commonalities and differences. Developmental Review, 8, 185-208.

Waterman, A. S. (1999). Identity, identity statuses, and identity status development: A contemporary statement. Developmental Review, 19, 591-621. 
Wisoot Binlatech. (2010). the process Of Sustaining Muslim Identities and Strong Community Building: The Case Study of Ban Nua Mosque Community, Khutao Subdistrict, Hatyai District, Songkhla Province. (Unpublished doctoral dissertation). Taksin University, Songkhla. Thailand.

Yeh, C. J., and Inose, M. (2002). Difficulties and coping strategies of Chinese, Japanese, and Korean immigrant students. Adolescence, 37, 69-82.

Yeh, C. J., Kim, A. B., Pituc, S. T., and Atkins, M. (2008). Poverty, loss, and resilience: The story of Chinese Immigrant youth. Journal of Counseling Psychology, 55, 34-48.

\section{Copyrights}

Copyright for this article is retained by the author(s), with first publication rights granted to the journal.

This is an open-access article distributed under the terms and conditions of the Creative Commons Attribution license (http://creativecommons.org/licenses/by/4.0/). 